11

\title{
Механизм влияния водорода на фазовый переход в пленках $\mathrm{V}_{2} \mathrm{O}_{3}$
}

\author{
(C) А.В. Ильинский, Е.И. Никулин, Е.Б. Шадрин \\ Физико-технический институт им. А.Ф. Иофрфе РАН, \\ Санкт-Петербург, Россия \\ ๑E-mail: shadr.solid@mail.ioffe.ru
}

Поступила в Редакцию 16 января 2021 г.

В окончательной редакции 16 января 2021 г.

Принята к публикации 21 января 2021 г.

\begin{abstract}
Показано, что в гидрированных пленках полутораоксида ванадия возникает избыток свободных электронов по сравнению с негидрированными пленками. Это приводит к сдвигу петель температурного гистерезиса термического фазового перехода изолятор-металл в область низких температур, то есть к уменьшению критической температуры $T_{c}$ фазового перехода. Интерпретация результатов основана на том факте, что $\mathrm{V}_{2} \mathrm{O}_{3}$ представляет собой сильно коррелированный материал, а фазовый переход в нем носит комплексный характер: электронный переход Мотта инициирует структурный переход Пайерлса. Показано, что атомы внедренного водорода локализуются на ионах кислорода, образуя с ними дополнительные $\sigma$-связи, термическое разрушение части которых приводит к увеличению концентрации свободных электронов в зоне проводимости гидрированных пленок $\mathrm{V}_{2} \mathrm{O}_{3}$.
\end{abstract}

Ключевые слова: окислы ванадия, фазовый переход изолятор-металл, сильнокоррелированные материалы, гидрирование, водород.

DOI: 10.21883/FTT.2021.05.50819.005

\section{1. Введение}

В последние годы не иссякает интерес к исследованиям фазового перехода (ФП) изолятор-металл в окислах ванадия, которые являются как модельными объектами для изучения свойств сильнокоррелированных материалов, так и перспективными материалами для создания технических устройств нового поколения. Неиссякающий интерес к упомянутой проблематике связан с появлением результатов, полученных с помощью современных методов исследования: пико- и фемтосекундной спектроскопии [1], с применением техники атомносиловой микроскопии [2], микро-рамановского рассеяния света [3], диэлектрической спектроскопии [4] и др. При этом интенсивно дискутируется вопрос о природе ФП в оксидах ванадия и, прежде всего, в диоксиде ванадия. Причиной этих дискуссий является то, что, как оказалось, ФП состоит из двух стадий, которые частично или полностью перекрываются как на температурной шкале при совершении термического ФП, так и во времени при фотоимпульсном инициировании его возникновения. В настоящее время проблема выяснения природы ФП в диоксиде ванадия в основном решена. В работах $[5,6]$ рассмотрена комплексная картина превращения фаз в $\mathrm{VO}_{2}$, в рамках которой показано, что ФП здесь состоит из двух стадий: электронного перехода Мотта и структурного перехода Пайерлса, которые выступают как отдельные, но взаимосвязанные элементы общей картины. Указанные стадии последовательно проявляют себя при переходе материала из одной фазы в другую, инициируя друг друга. Наряду с этим, вопрос о природе ФП в других окислах ряда Магнели, и в частности, в полутораоксиде ванадия, находится в данное время на начальной стадии изучения [7].

В связи с этим настоящая работа посвящена экспериментальному исследованию возможности управления параметрами ФП изолятор-металл в тонких пленках полутораоксида ванадия, и, в частности, воздействию гидрирования пленок на процесс совершения ФП, а также анализу полученных результатов. Преимущество подобного рода экспериментов состоит в том, что гидрирование пленок дает уникальную возможность контролируемым и обратимым образом изменять электрические и оптические свойства кристаллического материала. Действительно, атом водорода, входя в кристаллическую решетку и отдавая свой электрон в зону проводимости, создает ситуацию, при которой малый по размерам протон при своем внедрении не искажает решетку и не оставляет последствий при удалении атома водорода из решетки. Все исходные свойства нанокристаллических пленок сохраняются, на что указывают, среди прочего, и результаты рентгеноструктурных исследований. Данный экспериментальный прием ранее способствовал прояснению механизма ФП изолятор-металл в диоксиде ванадия [5], поэтому в настоящей работе этот прием вновь используется для получения информации о недостаточно изученных к текущему моменту времени свойствах другого окисла ряда Магнели - полутораоксида ванадия.

\section{2. Методика}

В работе использовались тонкие (600-1000 $\AA$ ) пленки полутораоксида ванадия, синтезированные на стеклянной прозрачной подложке толщиной $0.5 \mathrm{~mm}$ и площадью 
$15 \times 15 \mathrm{~mm}^{2}$. Синтез осуществлялся методом лазерной абляции - формирования плазменного факела мощным импульсом ИК-лазера на алюмоиттриевом гранате с неодимом с плотностью мощности $10^{7}-10^{9} \mathrm{~W} / \mathrm{cm}^{2}$ и длительностью импульса $20 \mathrm{~ns}$ с выбросом материала металлической мишени за счет генерации гиперзвуковых колебаний в ее приповерхностной области. Мишенью служил металлический ванадий, который находился в вакуумной камере при давлении $\sim 2 \cdot 10^{-5} \mathrm{~Pa}$. Над мишенью на расстоянии $10 \mathrm{~cm}$ помещалась подложка из $\mathrm{SiAl}$ толщиной $0.6 \mathrm{~mm}$, находившаяся в потоке кислорода, продуваемого вблизи на расстоянии $1 \mathrm{~mm}$ от ее поверхности. Температура подложек составляла $\sim 500^{\circ} \mathrm{C}$. Качество синтезированной окиснованадиевой пленки проверялось с помощью AFM-микроскопии, а ее толщина измерялась с помощью интерференционного микроскопа Линника МИИ-4М.

Температурные зависимости электропроводности пленок $\mathrm{V}_{2} \mathrm{O}_{3}$ и их оптического отражения измерялись в интервале температур 100-300 K. Для оптических и электрических измерений при низких температурах использовался сосуд Дьюара с жидким азотом. Температурная зависимость коэффициента отражения пленки регистрировалась на длине волны $1.4 \mu \mathrm{m}$. Датчиком температуры служила термопара состава „медь-константан“.

В экспериментах по измерению электропроводности и постоянных Холла на пленочные образцы наносились индиевые контакты. Постоянная Холла измерялась стандартным 4-зондовым методом при наложении магнитного поля с индукцией $0.1 \mathrm{~T}$.

Гидрирование пленок осуществлялось выдержкой образцов в горячем глицерине при $T=100^{\circ} \mathrm{C}$ в течение 1-100 min непосредственно перед регистрацией петель температурного гистерезиса. Измерения проводились многократно по мере естественного выхода водорода из гидрированной пленки, а также после принудительного удаления из нее водорода при нагреве на воздухе при температуре $250-300^{\circ} \mathrm{C}$.

Процесс гидрирования пленок методом термического разложения глицерина имеет свои особенности по сравнению с обычно применяемым гидрированием пленок выдержкой их в газообразном водороде [8]. А именно, термическое разложение глицерина $\left(\mathrm{C}_{3} \mathrm{H}_{5}(\mathrm{OH})_{3}\right)$ на воздухе при атмосферном давлении сопровождается отщеплением молекулы воды и превращением его на первом этапе в альдоль $\left(\mathrm{C}_{4} \mathrm{H}_{8} \mathrm{O}_{2}\right)$, а затем - в акролеин $\left(\mathrm{C}_{3} \mathrm{H}_{4} \mathrm{O}\right)$. Данные органические соединения насыщены водородом, связанным с атомами углерода $\sigma$-связями [9]. Акролеин проявляет высокую реакционную способность, и, в частности, эффективно соединяется с нуклеофилами [10,11], Подчеркнем, что нуклеофил представляет собой реагент, образующий химическую связь с партнером по химической реакции (электрофилом) по донорно-акцепторному механизму, предоставляя электронную пару, образующую новую связь. В роли нуклеофилов могут выступать любые ионы и нейтральные молекулы с неподеленной электронной парой.

Для случая нанокристаллитов пленки $\mathrm{VO}_{2}$ в роли нуклеофилов выступают ионы кислорода, расположенные в углах кислородных октаэдров, расположенных в приповерхностной зоне нанокристаллита. Молекулы акролеина, насыщая поверхность нанокристаллита, изменяют гибридизацию ионов кислорода. С конфигурации $2 s^{2}(1) 2 p_{x}^{1}(1) 2 p_{y}^{1}(1)$ (в скобках - число атомных орбиталей, участвующих в гибридизации, верхний индекс количество электронов на них) с тремя гибридными орбиталями на конфигурацию, при которой ионы кислорода образуют четыре $2 s^{2}(1) 2 p_{x}^{1}(1) 2 p_{y}^{1}(1) 2 p_{z}^{2}(1)$-гибридные орбитали, фиксируя на четвертой гибридной орбитали неподеленную электронную пару. Таким образом, каждый нанокристаллит пленки $\mathrm{VO}_{2}$ за счет донорноакцепторных связей оказывается окруженным акролеином - эффективным поставщиком атомов водорода. Мы полагаем, что аналогичное явление имеет место для нанокристаллитов пленки $\mathrm{V}_{2} \mathrm{O}_{3}$ с тем, однако, отличием, что ион кислорода в нанокристаллитах пленки $\mathrm{V}_{2} \mathrm{O}_{3}$ меняет свою гибридизацию с $2 s^{2}(1) 2 p_{x}^{1}(1) 2 p_{y}^{1}(1) 2 p_{z}^{2}(1)-$ конфигурации гибридных орбиталей на конфигурацию $1 p_{z}^{2}(1) 2 s^{2}(1) 2 p_{x}^{1}(1) 2 p_{y}^{1}(1) 2 p_{z}^{2}(1)$. Это увеличение числа гибридных орбиталей также создает дополнительную гибридную орбиталь с неподеленной электронной парой и позволяет за счет донорно-акцепторных связей насытить поверхность $\mathrm{V}_{2} \mathrm{O}_{3}$-нанокристаллитов акролеином - эффективным поставщиком водорода.

Процесс отщепления атомов водорода от молекул акролеина и особенности их диффузии в толщу нанокристаллитов описаны ниже в разделе „Обсуждение“.

\section{3. Экспериментальные результаты}

На рис. 1 приведено AFM-изображение пленки $\mathrm{V}_{2} \mathrm{O}_{3}$, которое демонстрирует однородную нанокристаллическую структуру пленки с размером кристаллитов около $150 \mathrm{~nm}$. Гистограмма на вставке к рис. 1 показывает, что нанокристаллиты пленки распределены по размерам в широком интервале: $20-400 \mathrm{~nm}$. Это обстоятельство определяет, как известно [12], разнообразие форм и физических параметров петель температурного гистерезиса окисно-ванадиевых пленок, что в литературе обозначается общим термином „мартенситность“. В данном случае речь идет о зависимости ширины элементарной петли нанокристаллита и температуры равновесия фаз в нем от его среднего поперечника и концентрации дефектов стехиометрии по кислороду, что обуславливает форму и ширину общей петли гистерезиса пленки $\mathrm{V}_{2} \mathrm{O}_{3}$. При этом если ширина элементарной петли обратно пропорциональна корню квадратному из среднего поперечника кристаллита (что определяется, согласно теореме Лапласа, избыточным давлением, создаваемым поверхностным натяжением наружной границы кристаллита), то для нелегированной пленки термическое по- 


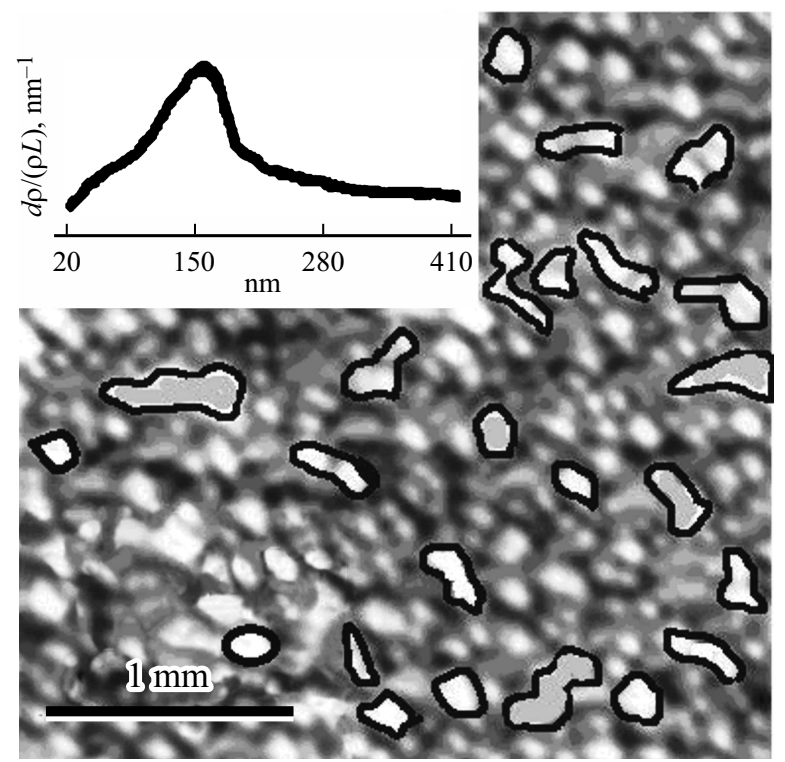

Рис. 1. Изображение пленки $\mathrm{V}_{2} \mathrm{O}_{3}$, полученное с помощью атомно-силового микроскопа. Выделены наиболее крупные нанокристаллиты. На вставке гистограмма распределения зерен по размерам. ложение середины петли (температура равновесия фаз) обусловлена степенью нестехиометрии нанокристаллита по кислороду, тем большей, чем больше средний размер нанокристаллита [13].

На рис. 2, $а$ в логарифмическом масштабе представлена температурная зависимость электропроводности негидрированной пленки $\mathrm{V}_{2} \mathrm{O}_{3}: \ln \sigma(T)$. Эта зависимость имеет нагревную и охладительную ветви, причем электропроводность пленки изменяется более чем на порядок при изменении температуры в пределах 100-300 К. Ветви формируют сравнительно узкую $(\sim 14 \mathrm{~K})$, но протяженную по температуре $(\sim 100 \mathrm{~K})$ петлю термического гистерезиса, которая свидетельствует о совершении в полутораоксиде ванадия ФП изолятор-металл. Отметим, что при высоких температурах удельная проводимость велика $(\sim 545 \mathrm{~S} / \mathrm{cm})$, а ее температурная зависимость носит специфичный характер: при монотонном увеличении температуры образца после продолжительного значительного роста наблюдается последующее слабое падение проводимости (вставка на рис. 2,a). Ширина петли температурного гистерезиса составляет $14 \mathrm{~K}$, „центр тяжести“ нагревной ветви петли (температура, соответствующая максимуму производной логарифма
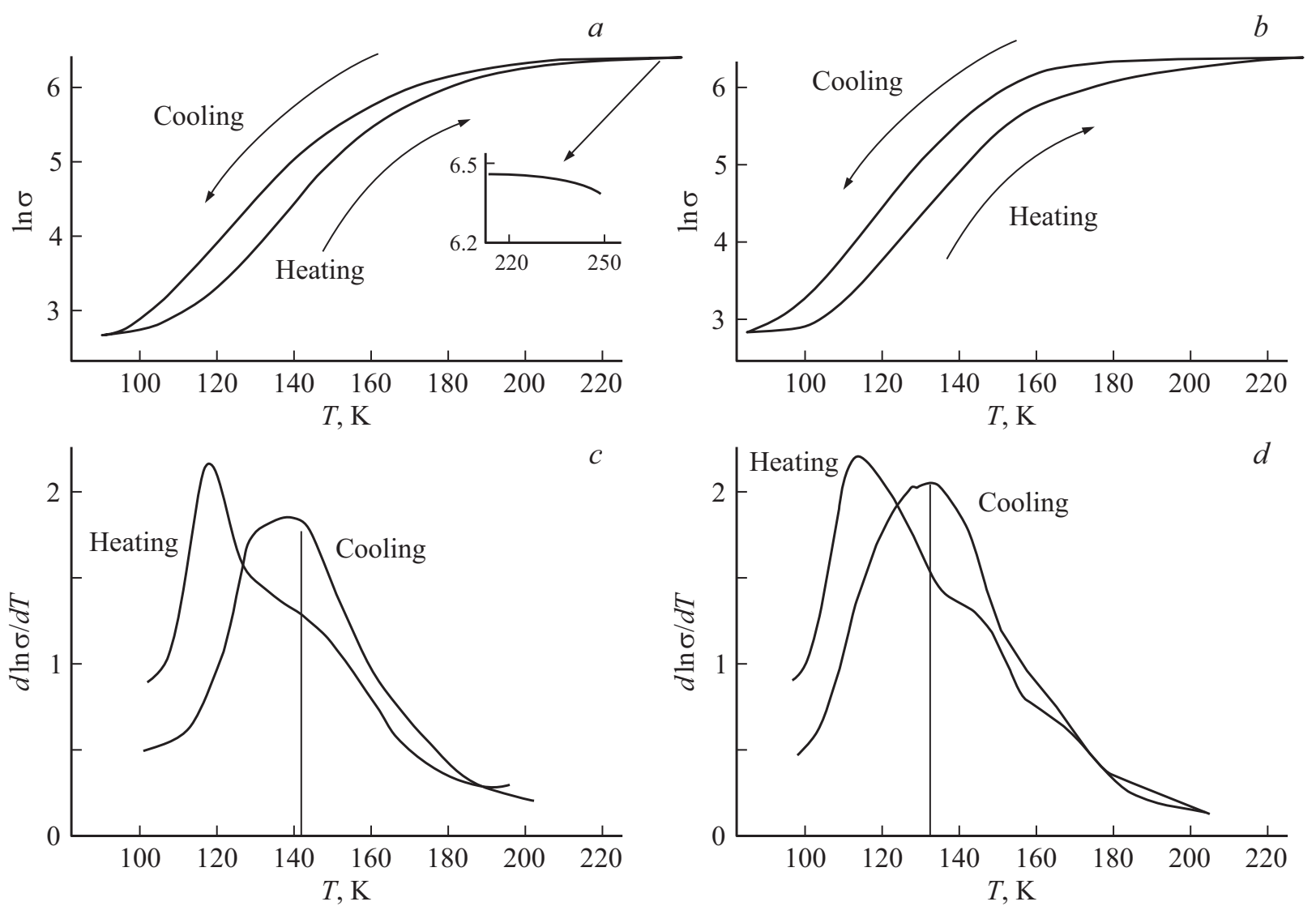

Рис. 2. Петли температурного гистерезиса электропроводности $(\ln \sigma)$ пленки $\mathrm{V}_{2} \mathrm{O}_{3}: a-$ негидрированной (протяженность ветвей $105 \mathrm{~K})$ и $b-$ гидрированной (протяженность ветвей $95 \mathrm{~K}$ ); $c$ и $d-$ производные по температуре ветвей петли гистерезиса, что позволяет с большей точностью определить $T_{c}$. 

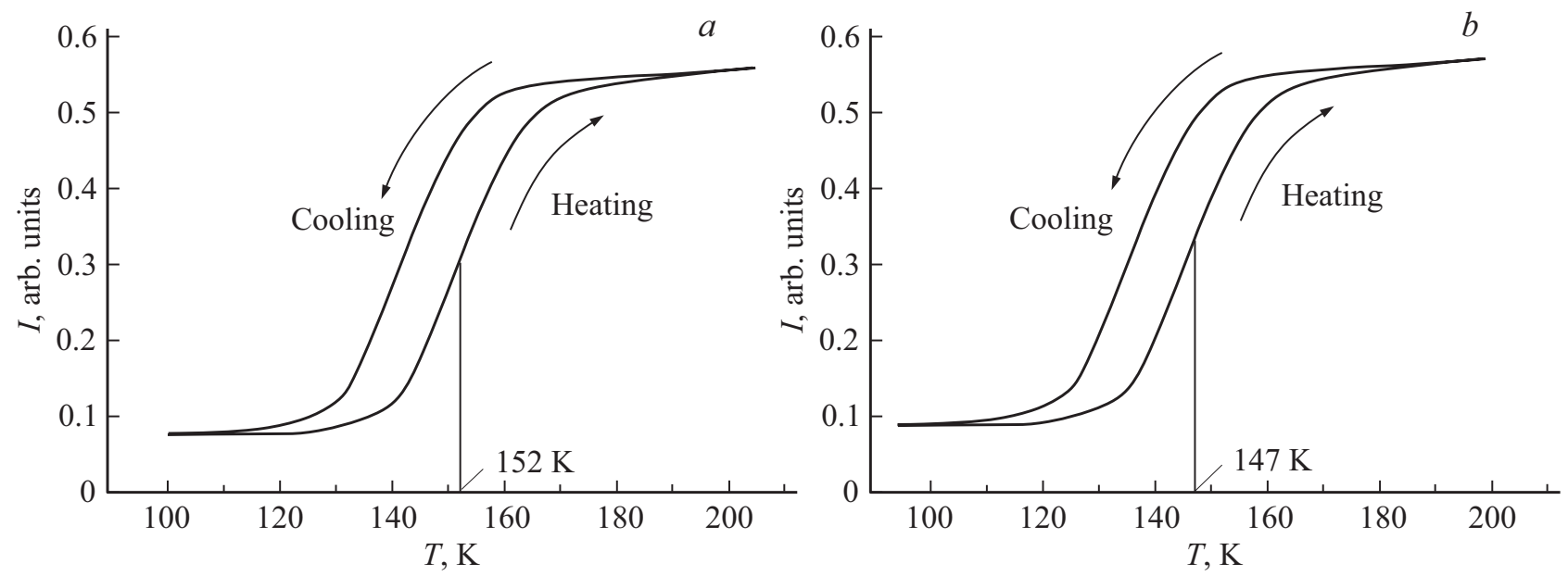

Рис. 3. Петли температурного гистерезиса интенсивности отраженного от пленки $\mathrm{V}_{2} \mathrm{O}_{3}$ света: $a-$ негидрированная пленка и $b$ - гидрированная пленка.

проводимости по температуре $d[\ln (\sigma)] / d T)$ соответствует температуре $T_{c}=140 \mathrm{~K}$. Эта температура принимается за температуру ФП изолятор-металл в пленке $\mathrm{V}_{2} \mathrm{O}_{3}$. На рис. $2, b$ представлена петля температурного гистерезиса электропроводности гидрированной пленки $\mathrm{V}_{2} \mathrm{O}_{3}$. В целом она подобна петле негидрированной пленки, но ее важной особенностью является сдвиг в область низких температур в среднем на $6 \mathrm{~K}$. Как следствие, температура ФП изолятор-металл для гидрированной пленки меньше, чем для негидрированной, и составляет $T_{c}=134 \mathrm{~K}$.

На рис. 3, $a$ представлена протяженная по температуpe (протяженность $120 \mathrm{~K}$ ) петля температурного гистерезиса коэффициента отражения негидрированной пленки $\mathrm{V}_{2} \mathrm{O}_{3}-I(T)$. Видно, что с ростом температуры образца интенсивность отраженного света растет (прошедшего сквозь пленку света - уменьшается) на порядок, а поверхность пленки приобретает характерный „металлический блеск“. Другими словами, при высоких по сравнению с $T_{c}=152 \mathrm{~K}$ температурах $(T=200-300 \mathrm{~K})$ кристаллиты пленки переходят в металлическую фазу. „Центр тяжести“ ветви петли, соответствующей нагреву образца, приходится на температуру $T_{c}=152 \mathrm{~K}$, ширина петли составляет $10 \mathrm{~K}$. Рис. $3, b$ демонстрирует аналогичную петлю температурного гистерезиса для гидрированной пленки полутораоксида ванадия. Отличие от негидрированного случая заключается в сдвиге петли гистерезиса на $5 \mathrm{~K}$ в область низких температур, то есть критическая температура ФП изолятор-металл при гидрировании уменьшается на $5 \mathrm{~K}\left(T_{\mathrm{cH}}=147 \mathrm{~K}\right)$. Нагрев до $370 \mathrm{~K}$ возвращает легированные водородом образцы в исходное состояние, откуда следует, что процесс гидрирования обратим.

Для пленок $\mathrm{V}_{2} \mathrm{O}_{3}$ измерены постоянные Холла $R_{h}$ при низкой $(T=95 \mathrm{~K})$ и высокой $(T=300 \mathrm{~K})$ температурах. Для негидрированной пленки $R_{h}=1200 \mathrm{~cm}^{3} / \mathrm{C}$ и $R_{h}=1.3 \mathrm{~cm}^{3} / \mathrm{C}$, соответственно. Для той же, но гид- рированной, пленки они оказались меньшими по величине: $R_{h}=1000 \mathrm{~cm}^{3} / \mathrm{C}$ и ${ }_{R} h=0.6 \mathrm{~cm}^{3} / \mathrm{C}$ соответственно. Численные значения постоянной Холла говорят об увеличении концентрации свободных электронов как при гидрировании пленок, так и при росте температуры образцов.

\section{4. Обсуждение}

Приведенные выше экспериментальные данные показывают, что полутораоксид ванадия $\left(\mathrm{V}_{2} \mathrm{O}_{3}\right)-$ кристаллический материал, испытывающий ФП изоляторметалл при температуре $T_{c}=140 \mathrm{~K}$. Известно [14], что при $T>T_{c}$ он представляет собой металл с ромбоэдрической (тригональной) симметрией решетки. При $T<T_{c}, \mathrm{~V}_{2} \mathrm{O}_{3}$ переходит в изолирующую фазу моноклинной симметрии, то есть совершается структурный ФП с изменением симметрии кристаллической решетки. Элементарная ячейка решетки $\mathrm{V}_{2} \mathrm{O}_{3}$ содержит в себе 4 атома ванадия и 6 атомов кислорода, что определяет строгое химическое обозначение как $\mathrm{V}_{4} \mathrm{O}_{6}$. Особенностью кристаллической структуры $\mathrm{V}_{2} \mathrm{O}_{3}$ является то, что в решетке на каждые два октаэдра, содержащие $\mathrm{V}^{3+}$ в основании, приходится один октаэдр, не содержащий иона $\mathrm{V}^{3+}$. Октаэдры с пустыми основаниями расположены по обе стороны от пары октаэдров с заполненными ванадием основаниями (рис. 4). В рамках теории валентных связей следует считать, что в элементарной ячейке $\mathrm{V}_{2} \mathrm{O}_{3}$ каждый атом ванадия в результате $3 d_{x y}^{1}(1) 3 d_{z 2}^{0}(1) 4 s^{2}(1) 4 p^{0}(3)$-гибриди -зации образует шесть $\sigma$-связей с шестью атомами кислорода в углах октаэдра. Каждый атом кислорода имеет четыре $2 s^{2}(1) 2 p_{y}^{1}(1) 2 p_{y}^{1}(1) 2 p_{z}^{2}(1)$-гибридные орбитали и создает четыре $\sigma$-связи с атомами ванадия. На рис. 4 эти $\sigma$-связи не указаны. Координационные числа ионов ванадия и кислорода равны 6 и 4 соответственно. 

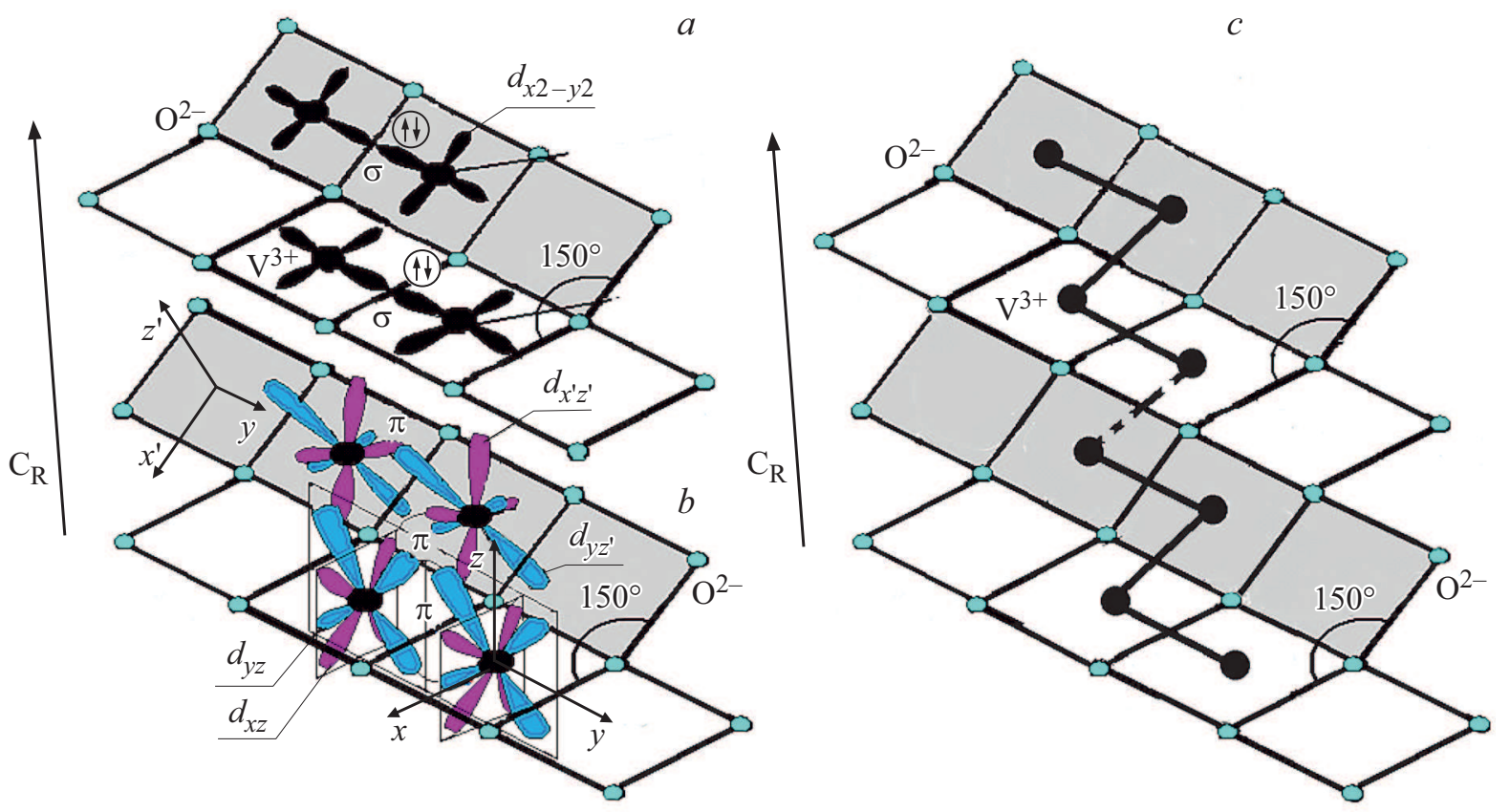

Рис. 4. Элементы кристаллической структуры $\mathrm{V}_{2} \mathrm{O}_{3} . a-$ взаимное расположение ионов $\mathrm{V}^{3+}$ в металлической фазе и $\sigma$-димеры, $b-$ взаимное расположение ионов $\mathrm{V}^{3+}$ в металлической фазе и $\pi$-связи, $c-$ схематическое изображение динамических $\pi$-связей, обуславливающих по зигзагообразной цепочке вдоль оси $C_{R}$ электропроводность материала в металлической фазе.

У каждого атома ванадия имеются 2 не занятых в формировании $\sigma$-связей электрона. Дело в том, что из 5 электронов верхних оболочек ион $\mathrm{V}^{3+}$ отдает на формирование $\sigma$-связей один электрон с $3 d_{x y}^{1}$-орбитали и два - с $4 s^{2}$. Поэтому один из незанятых электронов создает прочную $\sigma$-связь между $3 d_{x 2-y 2}-$ орбиталями ионов $\mathrm{V}^{3+}$ соседних октаэдров - см. рис. 4. Как следствие формируются прочные $\sigma$-димеры, которые не могут быть разрушены при нагреве вплоть до комнатной температуры. Их устойчивость как в изолирующей, так и в металлической фазах обусловлена тем, что к каждой паре октаэдров с ионами $\mathrm{V}^{3+}$ с обеих сторон примыкают пустые октаэдры. Второй электрон, не занятый в образовании $\sigma$-связей каркаса, равновероятно распределен между $3 d_{x z}$ и $3 d_{y z}$-орбиталями иона $\mathrm{V}^{3+}$. Эти орбитали перекрываются с орбиталями соседних ионов $\mathrm{V}^{3+}$, создавая в изолирующей фазе $\mathrm{V}_{2} \mathrm{O}_{3}$ два типа димеров: $3 d_{y z}-3 d_{y z}-\pi$-димеры, расположенные в одной плоскости и $3 d_{x z}-3 d_{x^{\prime} z^{\prime}}-\pi$-димеры, расположенные в плоскостях, наклоненных друг к другу под углом около $150^{\circ}$. Образование $\pi$-димеров при температурах ниже $T_{c}=140 \mathrm{~K}$ понижает симметрию решетки от ромбоэдрической до моноклинной. Поскольку л-димеры имеют, согласно иерархии энергий химических связей меньшую прочность, чем $\sigma$-димеры, то именно они разрушаются при нагреве до температуры $T>T_{c}$, то есть происходит структурный ФП из моноклинной в ромбоэдрическую фазу. Как показано на рис. 4,c, $\pi$-димеры образуют зигзагообразную цепочку вдоль кристаллической оси $C_{R}$. Период этой цепочки в ромбоэдрической фазе равен $d$, а в моноклинной фазе $-2 d$. По этой цепочке при высокой температуре в металлической фазе протекает ток за счет „квазидимеров“, т. е. периодически возникающих и разрушающихся динамических $\pi$-димеров, образующихся вследствие фононных колебаний решетки.

Сказанное представляет собой описание структурного ФП Пайерлса, и это описание объясняет тот факт, что ФП в полутораоксиде ванадия происходит при относительно низкой температуре $\left(T_{c}=140 \mathrm{~K}\right)$ по сравнению с диоксидом ванадия $\left(T_{c}=340 \mathrm{~K}\right): \pi$-димеры решетки $\mathrm{V}_{2} \mathrm{O}_{3}$ имеют меньшую энергию связи, чем $\sigma$-димеры решетки $\mathrm{VO}_{2}$. Однако известно [7], что ширина запрещенной зоны изолирующей фазы полутораоксида ванадия равна $E_{g}=0.2 \mathrm{eV}$, и поэтому при $140 \mathrm{~K}$ тепловая энергия $k T=0.026 \mathrm{eV}$ представляет собой величину, недостаточную для термического инициирования совершения структурного ФП.

Здесь уместно сказать, что для атома ванадия переходного элемента таблицы Менделеева с номером 23 - характерна сильная зависимость положения уровней энергии от их заселенности электронами. Это свойство атома ванадия наследуют и его окислы. В случае $\mathrm{V}_{2} \mathrm{O}_{3}$ при термическом заселении электронами зоны проводимости происходит сужение запрещенной зоны. Причиной сужения являются сильные электронэлектронные взаимодействия наряду со взаимодействием электронов с ядрами атомов. Поэтому сильные электрон-электронные корреляции играют принципиальную роль при совершении ФП в окислах ванадия. Впервые на такую возможность указал Мотт [15], и в 
современную физику вошло выражение „электронный фазовый переход Мотта“. Суть ФП Мотта заключается в том, что даже небольшое увеличения концентрации свободных электронов в зоне проводимости за счет термического разрушения небольшой части химических связей приводит к заметному сужению запрещенной зоны, что делает возможным новый заброс носителей за счет дальнейшего разрушения димеров уже при сравнительно низкой температуре (для $\mathrm{V}_{2} \mathrm{O}_{3}-$ $T_{c}=140 \mathrm{~K}$ ). Этому способствует тот факт, что распределение электронов по энергии в сильнокоррелированных материалах подчиняется не распределению Ферми, а распределению Мигдала, „хвосты“ которого на порядок больше Ферми [16]. Проверка данного положения естественным образом приводит к идее использования донорных свойств примесей, наиболее эффективными из которых является атомы водорода. Гидрирование пленки имеет также то преимущество, что оно может быть выполнено в лабораторных условиях без применения специального оборудования типа автоклавов высокого давления.

Однако при использовании метода гидрирования пленок окислов ванадия следует учитывать ряд специфических особенностей данного процесса. А именно, известно [17], что уже через одну минуту после окончания процесса гидрирования водород в таком окисле, как $\mathrm{VO}_{2}$ диффундирует в его металлической фазе на расстояние порядка $1 \mu \mathrm{m}$. В то же время процесс регистрации петли гистерезиса занимает десятки минут, которых, казалось бы, вполне достаточно для того, чтобы водород мог полностью покинуть исследуемую пленку с толщиной, на порядок меньшей $(0.1 \mu \mathrm{m})$. Однако значительная часть атомов водорода остается в пленке указанной толщины, так как эксперименты показывают, что под воздействием донорных свойств атома водорода температура $T_{c}$ снижается на десятки градусов в пленке $\mathrm{VO}_{2}$, и на несколько градусов в пленке исследованного в настоящей работе окисла $\mathrm{V}_{2} \mathrm{O}_{3}$ (рис. 2,3). Укажем также, что при предельно высокой гидрогенизации пленки $\mathrm{VO}_{2}$ она полностью металлизуется [5], причем ее удельное сопротивление, не завися от температуры в широкой области температур $(4.2-300 \mathrm{~K})$, оказывается на три порядка меньшим, чем у негидрированной пленки. Сказанное убеждает в том, что в окислах ванадия имеет место эффективное стабильное во времени гидрирование, причем значимого снижения удельного сопротивления пленки с ростом температуры в области электронного перехода Мотта $(270-300 \mathrm{~K})$ как в негидрированной, так и в гидрированной пленке такого окисла, как $\mathrm{VO}_{2}$, не наблюдается. Это говорит о завершении моттовской металлизации пленки (моттовского сужения до нуля ширины запрещенной зоны без изменения симметрии кристаллической решетки) для всех температур в области $4.2-300 \mathrm{~K}$, которое происходит вследствие сильного увеличения концентрации электронов в зоне проводимости при внедрении водорода. Более того, такое металлизированное состояние пленки сохраняется длительное время и может быть разрушено лишь интенсивным нагревом пленки до $300-400 \mathrm{~K}$.

Таким образом, не вызывает сомнения тот факт, что, несмотря на высокие скорости диффузии водорода в пленках окислов ванадия [17], в них длительное время сохраняется высокая концентрация атомов водорода, способная изменять электрические и оптические свойства материала. Механизм локализации атомов водорода, по нашему мнению, заключается в следующем.

В случае пленки такого окисла, как диоксид ванадия, в толще $\mathrm{VO}_{2}$ - нанокристаллита в окрестности внедренного в него атома водорода создаются условия для изменения стандартной гибридизации орбиталей иона кислорода $\mathrm{O}^{3-}$. А именно, три гибридные орбитали иона $\mathrm{O}^{3-}$ конфигурации $2 s^{2}(1) 2 p_{x}^{1}(1) 2 p_{y}^{1}(1)$ (три $\sigma$-связи) переходят в пять гибридных орбиталей с конфигурацией $2 s^{2}(1) 2 p_{x}^{1}(1) 2 p_{y}^{1}(1) 2 p_{z}^{2}(1) 2 d_{x y}^{0}(1)$. При этом на двух дополнительных гибридных орбиталях локализуется по одному электрону, что позволяет двум атомам водорода образовать две $\sigma$-связи с одним атомом кислорода. Для пленок полутораоксида ванадия имеет место аналогичная ситуация с той разницей, что структура гибридных орбиталей иона $\mathrm{O}^{4-}$ конфигурации $2 s^{2}(1) 2 p_{x}^{1}(1) 2 p_{y}^{1}(1) 2 p_{z}^{2}(1)$ (четыре $\sigma$-связи) при взаимодействии с атомами водорода изменяется на $1 p_{z}^{2}(1) 2 s^{2}(1) 2 p_{x}^{1}(1) 2 p_{y}^{1}(1) 2 p_{z}^{2}(1) 2 d_{x y}^{0}(1)-$ конфигурацию (шесть $\sigma$-связей). При этом на двух дополнительных орбиталях (содержащих по одному электрону на каждой) локализуются два атома водорода.

Итак, измененная водородом гибридизация иона кислорода приводит для $\mathrm{V}_{2} \mathrm{O}_{3}$ к появлению шести новых $\sigma$-связей иона кислорода: четырех с атомами ванадия и двух - с атомами водорода. Связи эти имеют меньшую энергию разрушения, то есть они менее прочны, чем четыре прежние $\sigma$-связи иона кислорода с ионами ванадия, фиксированными в центрах октаэдров, окружающих ион кислорода. Поэтому наряду с термическим разрушением небольшой доли $\pi$-димеров, что обеспечивало поставку электронов в зону проводимости при совершении моттовской стадии ФП [6], часть упомянутых низкоэнергетичных $\sigma$-связей ионов кислорода с ионами водорода также термически разрушаются, поставляя в зону проводимости дополнительные электроны от атомов водорода, что, в свою очередь, приводит к дополнительному сужению запрещенной зоны и к последующему снижению температуры $T_{c}$ структурного ФП. Согласно данным работы [8], высокая диффузионная способность атомов водорода внутри нанокристаллита определяется их прыжковой миграцией от одного иона кислорода к другому без изменения общего числа „водородных“ $\sigma$-связей и без существенных затрат энергии. В то же время для полного удаления в вакуум водорода из нанокристаллитов пленки при отсутствии акролеина на их поверхности необходимо разрушение большого числа „водородных“ $\sigma$-связей, и, кроме того, преодоление барьерного действия границы нанокристаллита, блокирующего выход, т.е. требуется значительная тепловая 
энергия, что достигается лишь существенным повышением температуры образца как минимум до $250^{\circ} \mid \mathrm{C}$.

Относительно конкретного механизма внедрения атомов водорода в кристаллическую решетку оксидов можно сказать следующее.

Как указывалось выше, поверхность нанокристаллитов $\mathrm{VO}_{2}$ и $\mathrm{V}_{2} \mathrm{O}_{3}$ адсорбирует и удерживает в себе молекулы акролеина за счет образования неподеленных электронных пар на дополнительных орбиталях ионов кислорода. Поскольку сорбционные процессы сопровождаются уменьшением поверхностной энергии Гиббса $G[18]$, то, согласно выражению $G=\sigma S$, (где $S$ - площадь границы раздела твердой и жидкой фаз, $\sigma$ - коэффициент поверхностного натяжения), процесс адсорбции акролеина понижает вместе с энергией Гиббса также и коэффициент поверхностного натяжения кристаллита и, тем самым, направленное внутрь него поверхностное давление. Выделяющийся при адсорбции акролеина избыток энергии способствует отрыву атомов водорода от молекул акролеина и преодолению ими энергетического барьера, что необходимо для входа атома водорода в толщу нанокристаллита. Концентрационная псевдосила, обусловленная градиентом концентрации атомов водорода между поверхностью и толщей кристаллита, осуществляет пассивный транспорт [19] и внедряет водород в кристаллическую решетку. Здесь он совершает прыжковую миграцию от одного иона кислорода к другому [8], последовательно изменяя при своем движении гибридизацию ионов кислорода и создавая временные дополнительные sigma-связи за счет энергии искривленной наружной поверхности нанокристаллита, создающей избыточное внешнее давление. При этом совершается работа, определяемая общим термодинамическим соотношением $\Delta A=\left(p_{\text {изб}}\right) \Delta V$. Сама энергия поверхностного натяжения запасается в процессе синтеза нанокристаллита с искривленной поверхностью, а ее воздействие тем больше, чем больше относительный вклад поверхностной энергии в общий термодинамический потенциал [20]. Численные значения поставляемой энергии велики, так как чрезвычайно велико поверхностное натяжение кристаллов, которое на порядки превышает поверхностное натяжение жидкостей [20].

Сказанное иллюстрируется тем примером, что процессу локализации атомов водорода в кристаллической решетке порошков $\mathrm{VO}_{2}$ способствует, как показано в [8], приложение к образцу внешнего механического напряжения. Аналогичное явление, согласно нашей концепции, имеет место, в частности, в нанокристаллических зернах пленок $\mathrm{VO}_{2}$. При этом процесс локализации ионов водорода в нанозернах пленки обладает той особенностью, что не требует приложения внешнего механического давления. В пленках, как указывалось, поверхностное натяжение нанокристаллических зерен создает, согласно теореме Лапласа, избыточное давление на внутренние области зерен, которое тем больше, чем меньше средний поперечник нанозерна и чем выше коэффициент поверхностного натяжения. Это избыточное давление увеличивает перекрытие атомных орбиталей в кристаллической решетке, упрочняя связи, а избыток выделяющейся при этом энергии модифицирует гибридизацию ионов кислорода согласно схеме, описанной выше, и обеспечивает присоединение молекул водорода к вновь образованным орбиталям ионов кислорода.

Процесс локализации атомов водорода в кристаллических пленках $\mathrm{V}_{2} \mathrm{O}_{3}$ протекает подобным же образом, но имеет свои особенности по сравнению с аналогичным процессом в пленках $\mathrm{VO}_{2}$. Пленки $\mathrm{V}_{2} \mathrm{O}_{3}$ имеют более рыхлую структуру кристаллической решетки из-за отсутствия атомов $\mathrm{V}$ в одной трети кислородных октаэдров (рис. 4), нанокристаллические зерна здесь существенно крупнее (на это указывают узкие петли гистерезиса рис. 2,3, параметры которых отражают мартенситный характер ФП). Поэтому они более чувствительны к действию механического сжатия, связанного с наличием поверхностного натяжения нанокристаллитов. Как результат, в зернах пленки $\mathrm{V}_{2} \mathrm{O}_{3}$ также локализуются атомы водорода на образовавшихся новых гибридных орбиталях ионов кислорода, возникших за счет избытка энергии, выделяющейся при росте перекрытия орбиталей кислородного октаэдра благодаря сжатию поверхностным давлением. Потеря водорода пленкой $\mathrm{V}_{2} \mathrm{O}_{3}$ оказывается так же, как в $\mathrm{VO}_{2}$, затрудненной. В результате возникает локализация атомов водорода в решетке $\mathrm{V}_{2} \mathrm{O}_{3}$. Однако по сравнению с пленкой $\mathrm{VO}_{2}$ и локализация и удержание атомов водорода в пленке $\mathrm{V}_{2} \mathrm{O}_{3}$ ослаблены из-за более рыхлой структуры решетки и меньшего поверхностного натяжения зерен. Последнее обусловлено как большими, чем в $\mathrm{VO}_{2}$, размерами зерен, что уменьшает избыточное лапласовское давление, так и значительно большим адсорбционным падением поверхностной энергии Гиббса из-за существенно большей площади поверхности нанокристаллитов, что дополнительно снижает $\sigma$. Сказанное объясняет экспериментальный факт более слабого корреляционного снижения $T_{c}$ при ФП для гидрированной пленки $\mathrm{V}_{2} \mathrm{O}_{3}$ (на 5-7 K) по сравнению с гидрированной пленкой $\mathrm{VO}_{2}$ (на $30 \mathrm{~K}$ ). Меньшее снижение $T_{c}$ обусловлено, подчеркнем, увеличенной по сравнению с $\mathrm{VO}_{2}$ потерей водорода крупными нанокристаллитами пленки $\mathrm{V}_{2} \mathrm{O}_{3}$. Итак, атомов водорода в пленке $\mathrm{V}_{2} \mathrm{O}_{3}$ существенно меньше, чем в пленке $\mathrm{VO}_{2}$, так как в последней и зерна мельче, и локализация атомов водорода существенно эффективнее. Поэтому $T_{c}$ в $\mathrm{VO}_{2}$ можно понизить гидрированием на $30 \mathrm{~K}$, а в $\mathrm{V}_{2} \mathrm{O}_{3}$ - лишь на 5-7 K, что мы и наблюдаем на опыте (рис. 2,3).

\section{5. Заключение}

ФП изолятор-металл в соединении $\mathrm{V}_{2} \mathrm{O}_{3}$ носит комплексный характер: электронный переход Мотта инициирует структурный переход Пайерлса. Проверить это утверждение экспериментально удалось, как показано в настоящей работе, методом гидрирования монокристал- 
лических пленок $\mathrm{V}_{2} \mathrm{O}_{3}$. Действительно, при внедрении атомов водорода в нанокристаллы пленок увеличивается концентрация свободных электронов, что подтверждают данные по исследованию их проводимости и отражательной способности. О таком увеличении свидетельствуют также данные выполненных нами измерений постоянных Холла. Увеличение концентрации электронов при гидрировании пленок сужает благодаря корреляционным эффектам запрещенную зону материала по сравнению с негидрированными пленками. Поэтому электронный переход Мотта инициирует структурный переход Пайерлса при меньших, чем без гидрирования, температурах. А именно, петли термического гистерезиса, как показано на рис. 2,3, смещаются в область низких температур. Итак, можно констатировать, что использованный в настоящей работе метод гидрирование позволил экспериментально подтвердить мотт-пайерлсовский характер ФП изолятор-металл в пленках $\mathrm{V}_{2} \mathrm{O}_{3}$.

\section{Конфликт интересов}

Авторы заявляют, что у них нет конфликта интересов.

\section{Список литературы}

[1] D. Wegkamp, J. Stáhler. Prog. Surf. Sci. 90, 464 (2015).

[2] T. Lin, J. Wang, G. Liu, L. Wang, X. Wang, Y. Zhang. Materials 10, 633 (2017). doi: 10.3390/ma10060633

[3] A. Tselev, A. Kolmakov, N. Lavrik, S. Kalinin. Adv. Funct. Mater. 23, 2635 (2013).

[4] А.В. Ильинский, Р.А. Кастро, М.Э. Пашкевич, Е.Б. Шадрин. ФТП 54, 4, 331 (2020).

[5] А.В. Ильинский, О.Е. Квашенкина, Е.Б. Шадрин. ФТП 45, 9, 1197 (2011).

[6] А.В. Ильинский, О.Е. Квашенкина, Е.Б. Шадрин. ФТП 46, 4, 439 (2012).

[7] А.В. Ильинский, Е.Б. Шадрин. ФТТ 62, 86, 1284 (2020).

[8] H. Ji. Hydrogen doping and the metal-insulator phase transition in vanadium dioxide. A thesis submitted in partial fulfillment of therequirements for the degree. Houston, Texas (2015). $160 \mathrm{p}$.

[9] H. Griesser, R. Öhrlein, W. Schwab, R. Ehrler, V. Jáger. Organic Syntheses 77, 236 (2000). doi: 10.15227/ 077.0236

[10] G. Ryder. World Social Protection Report (2018). 431 p. www.ilo.org/dyn/icsc/

[11] T.B. Phan, M. Breugst, H. Mayr. Angew. Chem. Int. Ed. 45, 3869 (2006). doi: 10.1002/anie.200600542

[12] Р.А. Алиев, В.Н. Андреев, В.М. Капралова, В.А. Климов, А.И. Соболев, Е.Б. Шадрин. ФТТ 48, 5, 874 (2006).

[13] И.С. Гибин, П.Е. Котляр. Прикл. физика 5, 44 (2019).

[14] K. Schneider. J. Mater. Sci.: Mater. Electron. 31, 10478 (2020). ttps://doi.org/10.1007/s10854-020-03596-0

[15] A. Zylbersztein, N.F. Mott. Phys. Rev. B 11, 4383 (1975). doi: 10.1103/PhysRevB.11.4383
[16] В. Вонсовский, М.И. Кацнельсон. Квантовая физика твердого тела. Наука, М. (1983). 341 с.

[17] T.F. Fuerst, E.P. Petsalis, S.T.B. Lundin, J. Wilcox, J. Douglas, W. Colin, A. Wolden. J. Phys. Chem. 122, 6, 3488 (2018).

[18] Г.Г. Хайдаров, А.Г. Хайдаров, А.Ч. Машек. Вестн. СанктПетербургского ун-та. Сер. 4. 1, 3 (2011).

[19] L.W. Barr. In: Diffusion in Materials, DIMAT 96 / Ed. H. Mehrer, Chr. Herzig, N.A. Stolwijk, H. Bracht. Scitec Publications 1, 1 (1997).

[20] Л.Д. Ландау, Е.М. Лифшиц. Теоретическая физика: Статистическая физика 9, 2, 480 (2004).

Редактор К.В. Емцев 